\title{
A AMPLIAÇÃO DO TEMA DO CONHECIMENTO EM RAIMUNDO LÚLIO
}

Esteve Jaulent *

SÍNTESE - Após afirmar que os dois sentidos aristotélicos do ato são insuficientes para dizer 0 ente tal como este se encontra na realidade, o trabalho mostra como o novo sentido que Lúlio atribuiu à noção de ato permitiu-lhe superar a limitação própria dos conhecimentos obtidos mediante as operações da faculdade cognoscitiva e alcançar, com ajuda de sua Ars, o ato de ser dos entes.

PALAVRAS-CHAVE - Raimundo Lúlio, teoria do conhecimento, conhecimento e ato.
ABSTRACT - After saying that the two senses of Aristotelian act are insufficient to express the being as it is in reality, this article shows how the new Lullian sense of act permits Lull to overcome the inherent limitation of knowledges obtained through the operations of the cognitive faculty and to reach, with the support of his Ars, the act of being of beings.

KEY WORDS - Raymond Lull, theory of knowledge, knowledge and act.

O tema do conhecimento tem dominado a reflexão filosófica desde seus primórdios. Embora a Filosofia aspire a dar uma explicação satisfatória do real, saber em que consiste o conhecer passa a ser uma condição prévia para o bom conhecimento da realidade, pois o acesso ao real só se torna possível ao homem mediante o conhecimento.

Contudo, se o conhecer pode abrir ao homem as portas do mundo efetivo e real, deve-se ao fato de ser muito mais do que um simples acesso à realidade. Arriscando ser talvez um pouco cru e forte, penso que se pode dizer que quando o homem conhece, forma as coisas conhecidas dentro de si. De fato, conhecer é dizer, expressar os entes dentro de nós, tal como estes se encontram na realidade. Ao longo da história a reflexão filosófica tentará mostrar quais são as dimensões dessas coisas que formamos dentro de nós ao conhecer, intentando penetrar cada vez mais no mistério dessa união pessoa/mundo que tem lugar no ato do conhecimento.

* Instituto Brasileiro de Filosofia e Ciência "Raimundo Lúlio".

\begin{tabular}{|l|l|l|l|l|l|}
\hline VERITAS & Porto Alegre & v. 43 & $\mathrm{n}^{2} 3$ & Setembro 1998 & p. $623-642$ \\
\hline
\end{tabular}




\section{ARISTÓTELES}

\section{O conhecimento como ato em Aristóteles}

Aristóteles deu um grande passo na compreensão do fenômeno do conhecimento ao dar-se conta da verdadeira natureza desse presencializar as coisas dentro de nós. Até Platão, o tema do conhecimento tinha-se colocado em termos de união da mente com o real. Em Platão, da mente com as Idéias, pois, segundo ele, estas eram o real por excelência. Contudo, só se pode unir o que já é em si; portanto, essa unificação da mente com as Idéias iria depender necessariamente de uma terceira realidade, que Platão situou no Bem, e em conseqüência, o conhecido, o resultante dessa união teria de ser necessariamente algo distinto ao que se unifica. ${ }^{1}$

Aristóteles penetra corretamente no que é o conhecer ao afirmar que é um ato. O importante achado aristotélico da teoria do ato e da potência teve lugar precisamente quando o Estagirita tentava explicar o fenômeno do conhecimento. Por conseguinte, tenha-se sempre presente de ora em diante que no aristotelismo se avança na compreensão do que é ato ao compreender-se melhor o que é o conhecimento; não o contrário.

Aristóteles dá-se conta que a ação que se realiza ao conhecer possui seu fim já desde o começo. Desde o início do conhecer estamos conhecendo. O mesmo poderia afirmar-se das operações do sentido da vista: mal começamos a ver, temos o visto; mal começo a pensar, tenho o pensado. Pensar, diz Aristóteles, é uma ação que não tem término, como o tem, por exemplo, a ação de construir uma casa. Enquanto construo, não tenho a casa. Ao terminar a construção, a casa está pronta e cessa o construir. Todavia, enquanto penso, já tenho o pensado; e terminando de pensar, o pensado desaparece. São duas ações de naturezas bem diferentes. Pensar é um ato imanente; construir uma casa, transeunte ou transitivo.

Conhecer é um ato que não tem término, porque seu fim se possui desde o início do ato; ou, em outras palavras, se ato é movimento e, querendo-se chamar movimento a esse ato de conhecimento, dever-se-á entender movimento num sentido bem diferente, muito mais perfeito, pois nesse caso trata-se de um movimento que já possui seu término desde o início e nem por isso cessa. Vemos e continuamos vendo; pensamos, e continuamos pensando. A rigor, näo se deve dizer que 0 ato de conhecer possui o seu término, mas seu fim. Conhecemos, temos o conhecido - que é o fim do ato de conhecer - e continuamos conhecendo, numa unidade total entre 0 ato de conhecer e o conhecido, isto é, a coisa enquanto conhecida.

Aristóteles alcança assim uma compreensão do que é o conhecer própria de um gênio. $\mathrm{O}$ conhecer, diz ele, é um ato que possui desde seu início o conhecido. Não é um ir até o conhecido, porque já o tem. É um ato extra-temporal. Mal abrimos os olhos, já vemos. Velocidade infinita. Não se trata de unir dois em si que estivessem separados, mas de dar-se conta de que, ao conhecer, ocorre um ato e também uma posse por esse ato. Há uma unidade perfeita entre ato de conhecer e o conhecido.

1 Para esta parte referente a Platão e Aristóteles cf. a sintese bem elaborada de Leonardo Polo, em Introducción a la Filosofia, Eunsa, Pamplona 1995, cap. 5 e 6. 
A esse ato de conhecimento Aristóteles denominou enérgeia. Repito que se compreende melhor a noção de ato na médida em que se descobre a indole do conhecimento, não o contrário. Ato significará, pois, atualidade, o atual, o que se está realizando agora. Porque o conhecido, simultâneo ao conhecer, é o que se está atualmente conhecendo. Enérgeia significa estar conhecendo.

A noção de enérgeia fica melhor definida se a distinguimos bem daqueles outros movimentos que apenas tendem para o fim, por não possuí-lo ainda. Quando estes movimentos alcançam seu fim, terminam nesse fim, que é seu término, porque são movimentos que têm a função de meios para o fim: ao atingi-lo, o móvel entra num estado mais perfeito, que Aristóteles denominará entelécheia. Antes de chegar a esse estado, porém, o móvel estará em potência, a potência que corresponde à entelécheia, uma potência temporal.

A enérgeia, todavia, é um ato extra-temporal. É o agora. Ao conhecer, o ato de conhecer tem o conhecido; mas quando não pensamos, quando não conhecemos, desaparece o ato e com ele o conhecido. Com a noção de enérgeia, por conseguinte, Aristóteles quer referir-se a um tipo de ato cognoscitivo que é uma operação. Nem sempre estamos conhecendo, pois nem sempre estamos pensando; mas quando não pensamos, por exemplo, quando dormimos, continuamos com a capacidade de pensar. Essa capacidade de pensar é a potência cognoscitiva; a potência que corresponde à enérgeia.

Aristóteles apresenta, portanto, dois sentidos de ato, ${ }^{2}$ com suas potências correspondentes. O primeiro deles, enérgeia, significa estar conhecendo a realidade, isto é, torná-la presente em nós numa operação de conhecer. Contudo a enérgeia não produz a realidade no seu ser extra-mental. Para o ato da realidade extramental, Aristóteles reservou outro termo: entelécheia, ato que constitui, ou ato que o Estagirita batizará como forma; mas, nesse caso, forma real, não pensada.

Para não perder a seqüência desta investigação, convém resumir o que até aqui se tem dito. Tanto o conhecer como a coisa real são atos, mas atos de naturezas diferentes. Ambos conferem realidade, mas dizem respeito a diferentes maneiras de ser real. $\mathrm{O}$ ato de conhecer é real e a coisa extramental também, mas não com a mesma realidade do ato de conhecer. $\mathrm{O}$ ato de conhecer está aberto a tudo; o ato do real fecha a coisa extramental na unidade de seu ser.

\section{A substância}

Uma vez penetrado no fenômeno do conhecimento com ajuda da noção de enérgeia, Aristóteles dará outro passo e descobrirá a substância. Definida a possibilidade de presencializarmos, mediante o conhecimento, todas as coisas dentro de nós, Aristóteles se perguntará a seguir pelo fundamento dos juízos mentais. Por que não afirmamos tudo de tudo, e somente afirmamos, ou negamos, umas coisas de outras? Responde o Estagirita dizendo que as coisas conhecidas não têm, cada uma delas, a mesma presença mental. É óbvio que, se a tivessem, seria impossível raciocinarmos e ficaríamos divagando sem saber como unir os distintos objetos de

2 Sobre este tema consulte-se Ricardo Yepes Stork, La doctrina del acto en Aristóteles, EUNSA, Pamplona 1993. 
pensamento. Aristćteles chegou ao ponto de afirmar que se a união entre esses objetos fosse só devida aọ acaso, melhor seria deixarmos de pensar e passarmos a viver como vegetais. ${ }^{3}$

Aristóteles denominará substância o que é representado pelo sujeito na proposição, e acidente o que é representado pelo predicado. A estrutura da proposição e a teoria aristotélica das categorias, na sua concepção, se correspondem.

Em resumo: a noção de substância surge, em Aristóteles, para fundamentar a ocorrência do pensar humano. Sem ela nos seria impossivel pensar e restariamos perplexos diante da infinidade de objetos que, graças à abstração, tornam-se presentes, a toda hora e sem descanso, em nossa mente. Pensamos "bola", pensamos "redonda" ou "gasta", e ao julgar coloçamos "bola" na condição de sujeito e "redonda" na função de predicado. Não unimos no pensamento os objetos "redonda". e "gasta", colocando um deles como sujeito do juízo, por carecerem qualquer um dos dois de estabilidade suficiente para serem sujeitos de inerência. De um deles não se pode dizer o outro, a não ser por acaso.

A noção aristotélica de substância origina-se portanto na observação da estrutura predicativa e ganha o estatuto de condição do pensamento, embora, é claro, não se reduza a isso. Todavia é verdade que sem substância não haveria juizos, e sem juizos não haveria pensamento. Se soubermos colocar no seu devido lugar sujeito e predicado, então poderemos formular juizos verdadeiros, juizos que expressem a adequação entre o intelecto e a realidade.

Contudo aparece neste ponto uma grave dificuldade que obstaculiza o progresso da investigação. No mundo real não se encontram nem sujeitos nem predicados. Com outras palavras, a substância pensada não é idêntica à substância real extramental. Por quê? Porque, como se viu, a substância real é ato - entelécheia mas a substância pensada, representada pelo sujeito da proposição, não o é: neste último caso, ato é a operação que a pensa. A substância pensada mantém-se presente no pensamento na medida em que seguimos pensando, senão desapareceria. O mais que se poderia dizer, portanto, é que a substância pensada no objeto de conceito terá atualidade somente na medida em que se mantenha a operação de pensar; mas em nenhum caso pode-se afirmar que, em si mesma considerada, seja ato.

De fato, a substância pensada, assim como também o acidente pensado, não são nem a substância nem 0 acidente reais. As coisas pensadas são objetos, e como tais, não são reais, mas intencionais. A dificuldade apontada acima consiste em que as categorias aristotélicas não são um modo de dizer o ente tal como este se encontra fora da mente. Que a "bola" seja "redonda" é, para Aristóteles, apenas uma questão predicativa e o Estagirita não nos explica por que a bola é redonda no mundo real.

A substância pensada, a que vem representada pelo sujeito da proposição, é a substância que a filosofia clássica denominará "substância segunda". Ela, e só ela, é suscetível de definição. Por este motivo Aristóteles afirma que o indivíduo é

3 Sobre a descoberta aristotélica da substância, cf. Leonardo Polo, El conocimiento habitual de los primeros principios, Cuademo n. 10 del Anuario Filosófico, Servicio de Publicaciones de la Universidad de Navarra S. A. Pamplona: 1991, p. 19-23. 
inefável e não se pode definir. Tanto o juizo aristotélico como toda a sua lógica demonstrativa usará apenas sentenças universais e nunca utilizará termos singulares ou individuais. ${ }^{4}$ Mais ainda, o silogismo perfeito aristotélico exigirá sempre um termo médio universal, o que só pode ser satisfeito pelo conhecimento duma substância segunda. ${ }^{5}$

Aristóteles era consciente de que $\mathrm{o}$ ato de conhecimento e $\mathrm{o}$ ato da substância real eram distintos. ${ }^{6} \mathrm{O}$ sentido primordial de ato remonta à enérgeia: uma ação que não cessa, mesmo possuindo seu fim; algo assim como uma ação que se repõe constantemente, sem pressupor nada. Assim, para Aristóteles, o atual é o pensado. A partir disso, 0 ato da substância real deveria entender-se, seguindo Aristóteles e aplicando a analogia, como uma atualidade que repõe constantemente $o$ ente na sua realidade extramental.

Mesmo que Aristóteles não pareça ter vislumbrado esse sentido do ato da substância real, pois segundo ele o principio de realidade do ente proviria da forma, está claro que as noções de enérgeia e entelécheia são insuficientes para explicar o conhecimento.

4 Aristóteles usou apenas sentenças universais (todo ou nenhum), particulares (algum ou algum não) ou indefinidas. Năo usou nunca termos singulares cu individuais. As sentenças indefinidas foram tratadas por ele como particulares e não têm nenhuma importância no sistema aristotélico de lógica. Foram suprimidas pelos lógicos posteriores que mantiveram só quatro tipos de sentenças: A (universal afirmativa), $\mathrm{E}$ (universal negativa), I (particular afirmativa) e O (particular negativa).

5 Aristóteles divide os silogismos em perfeitos e imperfeitos. "Chamo um silogismo perfeito quando não precisa de mais nada, fora o estabelecido, para tornar evidente sua necessidade". Isto significa que no silogismo perfeito a conexão entre $o$ antecedente e o conseqüente é evidente per se, sem nenhuma sentença adicional. São enunciados auto-evidentes e portanto não possuem nem precisam demonstração. São também denominados axiomas. Os silogismos imperfeitos não são autoevidentes. Uma sentença da forma " $A$ pertence a $B$ " é demonstrável se existe um termo médio, isto é, um termo que forme com $A$ e $B$ premissas verdadeiras de um silogismo válido e que tenha como conclusão a sentença " $A$ pertence a $B$ ". Se não existe esse termo, a sentença se denominará "imediata", isto é, sem termo médio. Ora, se um silogismo, por não ser auto-evidente, requer uma demonstração, como todo silogismo aristotélico é uma implicação, e portanto não tem sujeito nem predicado, inexiste nele qualquer termo médio. Por isso, a demonstração não pode ser feita por meio de um silogismo categórico. Isso levou Aristóteles a usar uma terminologia especial e assim, em vez de dizer que prova ou demonstra um silogismo imperfeito, diz que o reduz a outro perfeito. Com isso Aristóteles escapa de uma dificuldade. Para um silogismo ser demonstrativo requer-se o conhecimento dos primeiros princípios e da essência, porque o termo médio deve tomar-se, ao menos em uma de suas premissas, com toda a sua extensãc, ou segundo a sua universalidade. Para tanto, é imprescindivel conhecermos as essências ou espécies das coisas. Ora, o próprio Aristóteles nega que conheçamos as espécies. Segundo a teoria dos predicáveis, para conhecer a espécie é necessário também conhecermos a diferença especifica. Ignoramos a essência da mosca se não sabemos qual a diferença que acrescentada ao gênero animal, o determina como tal. Ora, fora a do homem (racionai), não conhecemos nenhuma cutra diferença específica de animal.

Por isso, Aristćteles, em vez de demonstrar um silogismo imperfeito, o reduz ao perfeito. Cf. Jan Lukasiewicz, La silogistica de Aristóteles desde el punto de vista de la lógica formal modema, Ed. Tecnos, Madrid, 1977, p. 45-46

6 Por este motivo, o campo abrangido pelo pensar é, em Aristóteles, mais amplo que o campo da realidade extramental, por ser a substância que faz de sujeito no juizo aristotélico a substância segunda e não a substância primeira. Podemos pensar "centauro", "sereia" e todos os entes de razão, sendo que nenhum deles terá, nem pode ter, existência fora da nossa mente. 


\section{Os dois sentidos aristotélicos do ato são insuficientes para dizer o ente tal como este se encontra extra animam}

Aristóteles distinguiu entre o campo lógico e o real, todavia não explicou suficientemente suas relações porque para isso seria necessária uma compreensão completa do que é o conhecer, algo impossivel de se fazer apenas com as duas noções de ato que o Estagirita descobriu.

Perguntar-se se existe o conhecimento é uma obsessão moderna. Na Antigüidade, como na Idade Média, admitia-se a existência do conhecimento e buscavase uma explicação para o mesmo. Era justamente isso o que pretendia Aristóteles quando plasmou a noção de enérgeia. Mas logo percebeu que a enérgeia - 0 ato do conhecimento - sendo um ato real, não era real no mesmo sentido que dizemos ser real a coisa extramental. Aristóteles distinguiu sempre entre realidade em sentido pleno, que é a realidade das coisas que são fora da mente, e a realidade do pensamento, que combina e separa, e dizia claramente que esta última "não pode indicar a existência de qualquer ente fora da mente". 7 A verdade do que se diz num ato de juizo é uma afecção do próprio pensamento, diz Aristóteles, e consiste no que se afirma ou nega do sujeito. É uma realidade puramente predicativa, que não nos informa sobre os princípios reais que fundamentam a coisa fora da mente. ${ }^{8}$ Ora, conhecer um ente não consiste apenas em saber o que ele é, isto é, conhecer sua essência; é preciso atingir também seu ato de ser. Não basta saber o que é; é preciso saber também que é.

Ao reduzir o tema do conhecimento aos atos que são operações - enérgeia Aristóteles fecha as portas para uma compreensão mais completa do conhecimento das realidades singulares, muito embora seja patente a todos que de alguma maneira conhecemos os indivíduos reais, as substâncias primeiras.

Com as operações cognoscitivas apenas nos informamos sobre as essências dos entes. Não se perca de vista que a enérgeia é um ato que possui o seu fim, isto é, a coisa conhecida, também chamada de objeto. Ora, o objeto é uma forma, a essência do ente conhecido.

Aristóteles transportou para o objeto a descoberta socrática do universal. O Estagirita explica que quando reconhecemos o mesmo conjunto de caracteres em vários indivíduos, a mente os unifica no conceito alcançando assim seu valor universal. É a essência, o quid dos escolásticos. Os objetos dos nossos conceitos referem-se sempre a algum quid, a alguma espécie ou essência, que Aristóteles classificou nas dez categorias.

7 Cf. Metafísica, VI-4, $1028^{a}$ 1-2, Editora Globo, Porto Alegre 1969, p. 146: “Com efeito, a causa do primeiro é indeterminada, enquanto a do segundo é alguma afecção do pensamento, e ambas se relacionam ao restante gênero do que é, não indicando a existência de qualquer classe separada de ser." Cf. também a exímia tradução de Moerbeke, In Metaphysicam Aristotelis Commentaria, Marietti, 1935, VI-4, $1028^{2}$ 1-2: "[.../ causa enim huius quidem indefinita, illius vero mentis aliqua passio, et utraque circa reliquum genus entis, et non extra ostendunt entem aliquam naturam entis".

"Quanto ao que "é" no sentido de ser verdadeiro ou de ser por acidente, o primeiro consiste no que o pensamento afirma ou nega do sujeito e é uma afeção do próprio pensamento; por isso não se buscam os principios do que "é" neste sentido, mas sim do ser exterior e independente" Cf. Metafisica, XI-8, 1065 23-24, Editora Globo, Porto Alegre, 1969, p. 239. 
Por outro lado, se mediante as nossas operações cognoscitivas conhecemos as essências nos conceitos, o ato que torna-real fora da mente todas as dimensões dessa essência conhecida escapa à operação. Porque esse ato não é objetivável pela operação. Por isso se diz que não é conceptualizável,

\section{A noção de objeto}

Cabe aqui lembrar a noção de objeto segundo o realismo aristotélico. O objeto não se identifica com a coisa, com o ente. Objeto é uma noção que implica relação a um entendimento - ob iacere, estar diante, estar presente; portanto, no realismo aristotélico distingue-se sempre entre a realidade própria do ente e a sua objetualidade. $\mathrm{O}$ objeto é o ente enquanto conhecido. $\mathrm{O}$ objeto é o possuído pelo ato de conhecer. Não é real, mas intencional - que significa que se relaciona com o ente extramental - e por isso mesmo o objeto nos conduz diretamente para a coisa, por ser a coisa enquanto conhecida. Aristóteles diz inúmeras vezes que o término ad quem da intencionalidade, isto é, aquilo a que se assemelham as espécies mentais, são as próprias coisas. Ser objeto é, portanto, ser término de uma relação, e isto é algo extrínseco à realidade do real, não intervém para nada na constituição do real enquanto real.

É por este motivo que o ato que torna real a coisa fora da nossa mente não é objetivável pela operação cognoscitiva. $\mathrm{O}$ ato da operação não pode possuir outro ato. Além do mais, a operação, ao expressar a forma universal, de alguma maneira a imobiliza: a forma tem a estabilidade própria da unidade que surge da junção das notas que integram o conceito, e é por isso mesmo incapaz de expressar o dinamismo do ato do real.

A operação cognoscitiva limita-se ao objeto, que é algo fixo e invariável. Leonardo Polo diz que as operações comensuram-se com os objetos ou, com outras palavras, que o objeto limita a operação: por isso, há mais realidade numa mosca que na mente de todos os pensadores, dizia Tomás. ${ }^{9}$

\section{A necessidade de um sentido mais pleno para 0 ato}

A experiência nos mostra, porém, que de alguma maneira alcançamos a realidade dos entes singulares. É certo que atingimos o ato de ser dos entes, assim como é certo também que conhecemos os próprios atos das operações de conhecer. Quando conhecemos "bola" damo-nos conta de que estamos conhecendo "bola". Verifica-se isto igualmente com todos os outros sentidos: percebemos que estamos vendo, que estamos ouvindo, cheirando, etc. Percebemos, pois, que estamos pensando, que é o mesmo que dizer que alcançamos o ato individual e singular do nosso pensar. É necessário concluir, portanto, que há em nós outra instância de conhecimento além da operação da faculdade.

9 Cf. Leonardo Polo, El conocimiento habitual de los primeros principios, Cuademo n. 10 del Anuario Filosófico, Servicio de Publicaciones de la Universidad de Navarra S. A. Pamplona, 1991, p. 8. 
O tema não é novo. Ao longo da história muitos autores, e toda a filosofia tradicional, apontaram que o conhecimento via objeto, o conhecimento intencional, é parcial. Escoto parece ter sido o primeiro a levantar expressamente a suspeita de que a abstração aristotélica era um engano ou uma ficção, provocando deste modo a obsessão de ater-se ao empírico, via intuição. A partir dele, começou a separarse a coisa e o objeto, e esta separação caracterizará toda a filosofia moderna. A busca de mais uma instância para o conhecer é pois um problema antigo; se não parece que se tenha encontrado uma solução definitiva até o momento, ao menos as tentativas têm sido diversas.

Ciente de que os dois sentidos aristotélicos de ato não bastam para dar uma definição completa do que é o conhecer, Tomás lembrará que Deus, sendo Ato Puro, é também o Conhecer Subsistente - Ipsum intelligere subsistens. Como em Deus não se encontram potências ou faculdades, Tomás abre assim as portas para um novo modo de considerar o conhecimento a partir do ato de ser.

Por um lado, Tomás corrige o caráter predicativo das categorias aristotélicas ao afirmar que o princípio de toda espécie e forma é a própria Sabedoria divina claritas Dei est principio omnis specie et formae ${ }^{10}$; por outro, retifica os sentidos aristotélicos de ato dizendo que ato é ser. Portanto, se, como dizia Aristóteles, conhecer é ato, agora pode-se já dizer que conhecer é um modo de ser, abrindo-se assim as portas para uma consideração do conhecimento que vai além do tema da faculdade. Tomás, infelizmente, não investiga a fundo esta questão. Leonardo Polo sugere que o Aquinate não o fez porque fazê-lo exigiria ter revisto a noção aristotélica de substância. ${ }^{11}$

Esse novo modo de abordar o tema do conhecimento permitirá, sem dúvida alguma, dilucidar também a importante questão da inserção dos conhecimentos no ser cognoscente mediante os hábitos intelectuais. Aristóteles já se referiu a eles quando estudou o que ele chamou de "conhecimento habitual" que, à diferença da memória, retém 0 atual-conhecido e não o passado-conhecido, permitindo desta maneira ver com claridade crescente a unidade dos conhecimentos.

À luz de todas estas dificuldades, tornar-se-á mais compreensível o que Lúlio disse sobre este tema.

\section{RAIMUNDO LÚLIO}

Qual foi a postura do bem-aventurado maiorquino com relação aos pontos acima considerados? Nesta segunda parte do trabalho analisaremos alguns textos lulianos relacionados com o tema do conhecimento, contribuindo assim para elucidar sua posição, pelo menos a respeito dos seguintes pontos: o sentido do ato, a superação da limitação própria ao conhecimento objetivo, o conhecimento do ato do ser dos entes, a noção de substância e a incorporação do conhecido no ser da pessoa.

10 Cf. Super Epistolas S. Pauli Lectura, Ad Rom., n. 135, Marietti, Romae, 1953, p.25

11 Cf. Leonardo Polo, id., p. 19. 


\section{O sentido do ato em Lúlio}

A aporia que nos deixou Aristóteles no que diz respeito ao tema do conhecimento tem a sua raiz na dificuldade de unificar 0 ato do conhecimento, interpretado por ele como operação - enérgeia - com o ato do real - entelécheia - por serem atos de natureza diferente: o primeiro, um ato exercido; o segundo, um ato constitutivo da substância. Atos tão diferentes só poderiam unificar-se encontrando para a noção de ato um sentido metafísico mais elevado; um novo sentido que admitisse tanto o poder ser exercido como o poder ser constitutivo de uma substância. Não resta dúvida que um sentido tão excelente é preenchido pela noção de ser. Ato será, pois, ser, disse Tomás. Se Aristóteles interpretou o conhecimento como ato, Tomás interpretou o ser como ato. Raimundo Lúlio não apenas continuará a interpretação tomista senão que a tornará uma das colunas principais do seu pensamento para explicar a estrutura ontológica dos entes.

A totalidade dos entes, abstratos e concretos, é vista por Lúlio como uma constelação de atos de ser. A própria criação teria um caráter profundamente ativo. Consiste, diz ele, num único ato de Deus pelo qual dá o ser e o mantém nele em todos os gêneros, espécies e indivíduos, cada um no seu tempo e lugar. Cada ente, por sua atividade própria, tende a aumentar a perfeição concreta do universo.

No lulismo, os entes aparecem como que sustentados num, ou em diversos atos de ser (esse). Segundo Lúlio, cada ente finito é sujeito de um ato de ser e duma essência, esta última relacionando-se com o sujeito do ato de ser, como o abstrato relaciona-se com o concreto. Assim como algo bom, diz o maiorquino, é o concreto de uma bondade indicada pela essência, de um modo geral pode-se afirmar que o sujeito de um ato de ser (esse) é o concreto da própria essência.

A essência, no seu entender, é algo nocional, com uma positividade que consiste em dar consistência ao ato de ser. ${ }^{12}$ Desta maneira Lúlio consegue unificar o mundo do pensamento e o mundo real, o abstrato e o concreto, no ente-sujeitoindividual. Teria lido o Doutor lluminado o comentário de Tomás aos Romanos? ${ }^{13}$ Nele, como vimos, afirma-se que o principio de todas as formas ou essências, substanciais ou acidentais, seria a claridade do conhecimento divino. Pois bem, Lúlio, ao manter para a essência este caráter de pensado - consideratum - e ao sustentá-la, ao mesmo tempo, no ato próprio natural de ser do ente, iluminou maravilhosamente a dependência em Deus de todo ser e operar.

12 Essentia est aliquid confusum, consideratum, per quam esse est consistens, quoniam sicut bonum est concretum suae bonitatis, quae sua essentia est, sic esse est concretum essentiae. Cf. Raimundus Lullus, Die neue Logik - Logica Nova, Felix Meiner Verlag - Hamburg, 1985, Textkritisch herausgegeben von Charles LOHR, p. 170.19.

13 É bem provável, pois Glorieux coloca a expositio das epístolas paulinas como tendo sido feita por Tomás em Paris, entre 1270 e 1272 . Quinze anos depois, Lúlio se encontraria naquela cidade, primeiro em 1286, por motivo da celebração do capitulo geral dos dominicanos, e depois de 1287 a 1289, ensinando a sua Arte na Universidade. Cf. James A. Weisheipl, Tomas de Aquino, vida, obras y doctrina, EUNSA, Pamplona 1994, p. 426-427 e Raimundo Lúlio, Livro do amigo e do Amado, introd: trad. e estudos de Esteve Jaulent, Edições Loyola, São Paulo 1989, p. 25. 
É importante insistir nessa concepção tridimensional que Lúlio atribui à estrutura ontológica de qualquer ente, pois nela se baseia a ampliação do tema do conhecimento para além do estrito poder da faculdade. A este tema dedicou o Liber de Potentia, obiecto et actu, que teria escrito em Roma por volta de 1296. É num ato de ser que o sujeito possui, em perfeita unidade, a essência. Ou, com palavras do próprio maiorquino, o "ato" é o conectivo de uma "potência" e um "objeto"14. Estes três elementos, "potência", "objeto" e "ato" são tomados em sua maior generalidade e constituem o real, qualquer categoria que se considere do mesmo, e se encontram de tal modo unificados que não se pode definir um deles sem entrarem os outros na definição. A "potência" manifesta-se pelo seu "ato", mas de tal modo que tal "ato", sem sua "potência", não poderia ocorrer. Por sua vez, o "objeto" indica o "ato", pois sem ele, o "objeto" não estaria presente no "ato". Os três elementos formam pois um todo único, colocando-se o "ato" como um conectivo, ou médio entre a "potência" e o "objeto"15. Finalmente, cabe destacar a simultaneidade da ocorrência dos três elementos e, em decorrência dela, a sua extra-temporalidade.

Por outro lado, convém assinalar que o termo "potência" em Lúlio não é unívoco, como também não o será o termo correspondente "objeto", conforme se verá logo a seguir e no ponto seguinte. "Potência" toma-se em vários sentidos, pois por ela adquire-se tanto o "objeto próprio" como o "objeto apropriado". Lúlio chama de "objeto próprio" ao que corresponde à essência da "potência", da qual é o objeto. Os "objetos próprios" são todos eles objetos substanciais, isto é, habituam a substância onde se encontram: De modo diferente, os "objetos apropriados" são objetos acidentais, externos e vizinhos, dos quais se nutre o "objeto próprio", mediante a conversão do externo em algo próprio ${ }^{16}$. Um exemplo esclarecerá a questão. $\mathrm{O}$ "objeto próprio" do intelecto é entender sua própria inteligibilidade e intelectualidade, coisa impossivel de se fazer sem entender ao mesmo tempo outros "objetos apropriados", isto é, as inteligibilidades externas a ele. Sem "objetos apropriados" as "potências" no podem situar-se perante seus "objetos próprios". "Como a luz da lâmpada vive do óleo, assim o objeto próprio vive do apropriado e dele extrai alimento e natureza apropriada." 17 Mais ainda, faltando "objetos apropriados", arruinam-se as próprias substâncias, por não poderem ter lugar seus "atos" ao carecerem de "objeto próprio".

14 Vejam-se as citações do Liber de potentia, obiectu et actu em Jordi Gayà, La Teoria luliana de los Correlativos, Palma de Mallorca 1979, p. 121-122.

15

Potentia est ens, de genere potestatis per suum actum indicatum, eo quod actus sine potentia esse non potest. Obiectum est habitus suum indicans actum, quoniam sine ipso obiectum non esset obiectatum. Actus secundarius est medium inter potentiam et obiectum positum. Cuius ratio est, quia sine ipsis esse non potest cf. Raimundus Lullus, Die neue logik - Logica Nova, opus cit. p. 176, n.60, 61 e 62.

16 Cfr. Thomas Le Myésier, Breviculum, Pars Dispositiva, V, 2, 1. 78-83, Corpus Christianorum Continuatio Mediaevalis, vol. LXXVI, Brepols, Turnholt 1990, p.99. "Obiectum appropriatum est per accidens, et est illud extraneum propinquum, de quo vivit proprium per conversionem extranei in proprium."

17 Id. 1. 118-122, p.100. "Sicut lumen in lampade vivit de oleo, ita obiectum proprium vivit de appropriato, et de eo assumit nutrimentum et appropiatam naturam."

sory 
Da mesma maneira será necessário diștinguir entre "atos próprios", ou substanciais, e "atos apropriados", ou acidentais. Os primeiros permanecem graças aos segundos, como a chama, que é o ato do fogo, permanece na medida em que permanece $o$ ato de queimar a madeira.

Deste modo, vemos como o sentido de enérgeia - um ato extra-temporal, que possui desde o início seu fim e nem por isso cessa - que Aristóteles aplicou ao conhecimento, Lúlio o aplica a todos os entes: todo ato assim definido é feito e está in fieri, porque se não fosse feito, não seria; e se cessasse, extinguir-se-ia. ${ }^{18}$ Se Aristóteles podia dizer que num ato de conhecimento se conhece, se tem o conhecido e se continua conhecendo, com Lúlio podemos afirmar que, com o seu ato interior de ser, o ente é, se mantém estável naquilo que é, e continua sendo.

\section{A superação da limitação própria ao conhecimento objetivo}

Na primeira parte deste trabalho postulava-se a necessidade de se descobrir mais alguma instância para o conhecimento que permitisse explicar nosso contato, patente a todos, com o real, dado que o conhecimento operativo, possuidor de objetos (termo agora novamente entendido em sentido clássico e não luliano), é um conhecimento parcial, que nos diz o que são as coisas, mas não se estas são reais. Quando conhecemos de maneira objetiva, separamos o ser do objeto. Conhecer objetivamente serve, pois, para iluminar o real, mas não para conhecermos o ser do real.

A dificuldade, dizia-se acima, era conhecida de longa data e foi apontada inúmeras vezes. Era de se esperar, pois se nos damos conta de que conhecemos, de alguma maneira já superamos o limite da operação e esta superação é indicativa de uma nova instância de conhecimento.

Para alguns, esta nova instância adquire tanta importância que opinam teria de ser ela o ponto de partida da filosofia e não a razão, que apenas relaciona e acumula objetos. Schelling apontou para a necessidade de dar-se o que ele denominou "êxtase da razão", isto é, um "situar-se fora de si", mais exatamente, fora da razão, para que o conhecimento humano possa instaurar-se no próprio Absoluto.$^{19}$ Leonardo Polo, para superar esta dificuldade, apresenta o método que denominou de "abandono do limite mental". Partindo do pressuposto que o limite é o objeto, e correlativamente a operação, abandonar o limite, segundo Polo, não significará anulá-lo, o que seria impossível, mas ir além do conhecimento objetivo limitado, mediante a luz de uma nova instância de conhecimento que Polo situa nos hábitos intelectuais.

18 Id. 1. 178-182, p. 100. "Omnis actus definitus per definitionem antedatam est factus et est in fieri, quoniam, si non esset in facto esse, non esset. Et si cessaret, deficeret, sicut flamma ignis, quae facta est et in fieri est, quia comburendo durat et est."

19 Cf. F. W. J. Schelling, Initiae Philosphiae Universae, ErlangerVorlesengen 1820/21, org. H. Fuhrmans, Bonn; H. Bouvier u. Co. Verlag, 1969, p. 39, citado por Fernando Rey Puente, Algumas notas sobre o conceito de "enérgeia" como eixo da articulação entre a filosofia negativa e a filosofia positiva no pensamento tardio de Schelling, Sintese Nova Fase, Belo Horizonte, v. 22, n. 70, 1995, p. 396. 
Qual é nova instância de conhecimento sugerida por Lúlio? Antes de responder, precisamos destacar uma particularidade terminológica. Ao relacionar a noção de objeto com a de potência, entendida esta na sua maior extensão possivel, Lúlio amplia também a noção de objeto, incluindo neles tanto as formas possuidas pelos atos de conhecimento que são operações como os atos de ser do real. Se na ausência desses atos de ser não haveria realidades, sem objeto (agora entendido amplamente como manifestação de um ato de ser), também não haveria 0 objetado, diz o maiorquino, mostrando desta maneira como o termo objeto é uisado por ele para referir-se também ao ser do real.

Segundo Lúlio, captamos o ser do real mediante a potência intelectiva ou intellectus. Com efeito, quando conhecemos algo, nos damos conta ao mesmo tempo de que conhecemos esse algo, e portanto conhecemos o nosso ato de conhecer, e também com ele o nosso ato de ser. É claro que não se trata de um conhecimento essencial, mas do conhecimento de algo individual e singular, e portanto incomunicável. Não resta dúvida, porém, de que é um conhecimento do próprio ser; assim como também conhecemos que esse nosso ser não é o ser no qual se realiza a essência desse algo que estamos conhecendo. Há pois um duplo plano em cada ato de conhecimento. Se não se conhecesse o próprio ser estaríamos impossibilitados de conhecer as outras coisas como diferentes de nós mesmos; portanto, além da essência da coisa que conhecemos, conhecemos também o nosso ser e o ser da coisa.

Com palavras de Lúlio, "o intelecto que entende algum objeto tem um duplo entender. Por um lado, entende o que é próprio de sua essência e de sua ação e paixão substancial; por outro, entende o adquirido mediante o hábito da ciência, relacionando-se com os objetos dos sentidos particulares e seus atos", ${ }^{20}$

Foi, pois, a distinção luliana entre ato próprio ou substancial e atos apropriados ou acidentais, o instrumento que nos abriu caminho para estabelecer o estatuto de uma nova instância de conhecimento. A explicação é a seguinte: como o Intelecto divino é uma substância e é infinito, daí deduz Lúlio que a potência intelectiva atinge seu objeto mais substancialmente que acidentalmente, e portanto não lhe repugna - muito pelo contrário, lhe é muito conveniente - que o intelecto humano tenha também um ato substancial com o qual possa atingir-se a si próprio. ${ }^{21}$ Este ato substancial não nos fornece uma notícia objetiva da essência do próprio entendimento, mas uma percepção intelectual habitual de seu ser e de suas correspondentes inclinações naturais. É a nova instância de conhecimento.

20 "Intellectus, qui intelligit aliquod obiectum, habet duplex intelligere, quoniam unum est intelligere, quod simpliciter de sua est essentia et quod est de substantiali actione et passione. Aliud est intelligere acquisitum per habitum scientiae, se habens ad subiecta sensuum particularium et ad eorum actus" Cf. Thomas Le Myésier, Breviculum, Pars Dispositiva, XIX, Corpus Christianorum Continuatio Mediaevalis, vol. LXXVII, Brepols, Tumholt 1990, p. 170, 1. 47-51.

21 "Quoniam intellectus Dei est substantia et est infinitus, est et magis conveniens, quod humanus intellectus ipsum inteligat com potentia substantiali, et quod habeat actum substantialem, quod, si ipsum intelligeret cum potentia accidentali et cum actu accidentali, cum ita sit, quod potentia melius est plus attingere potest substantialiter quam accidentaliter. Habet ergo intellectus substantialem potentiam activam et substantialem actum et per consequens substantialem objectum" Cf. Thomas Le Myésier, Breviculum, Pars Dispositiva, XIX, Corpus Christianorum Continuatio Mediaevalis, vol. LXXVII, Brepols, Turnholt 1990, p. 169, 1. 33-40. 
Por outro lado, o entendimento se relacionará também com todos os outros objetos e atos acidentais para assim poder relacionar-se com seu objeto e ato substancial. Já se constatou acima a impossibilidade de o intelecto entender sua própria inteligibilidade e intelectualidade sem entender ao mesmo tempo outros "objetos apropriados". No lulismo, se as "potências" carecem de "objetos apropriados" não podem situar-se perante seus "objetos próprios". Como a luz da lâmpada vive do óleo, assim o entendimento só pode ter consciência de si mesmo com atos acidentais de conhecimento, que a filosofia clássica chamará de operações.

Resolve-se desta maneira a dificuldade que se colocava Agostinho, em decorrência de considerar a mente essa mirada permanente que a alma tem de si mesma. Ao ter a alma, por sua imaterialidade, a própria posse de seu ser, deveria estar sempre presente a si mesma. Mas então, dizia Agostinho, "não posso compreender como a mente, quando não pensamos, não está na sua presença, quando não poderia estar nunca sem ela, como se fosse a mente uma coisa e outra distinta o olhar que ela tem de si mesma."22 Segundo Lúlio, há necessidade de se realizar algum ato de conhecimento para poder-se efetuar o "ato próprio".

Lúlio supera pois o limite próprio ao conhecimento objetivo ou por operações. Basta entender bem sua noçâo de potência. Numa glosa aposta no reverso da página 99 do manuscrito do Breviculum, o autor insiste na necessidade de se conhecer adequadamente as potências, seus objetos e seus atos, por serem nomes equívocos. Contudo, bem compreendidas essas noções, se encontrará o caminho para julgar o próprio conhecimento objetivo, aceitando-o ou rejeitando-o em função deste outro conhecimento habitual que se tem do próprio ato de conhecimento, da realidade do objeto conhecido e da realidade do próprio entendimento.

O glosador esclarece que, como mostra a experiência quotidiana, é um fato que conhecemos a verdade dos entes; mas, para tanto, freqüentemente o entendimento precisa abandonar-se a si mesmo e até transcender-se capturando e até negando seu próprio entender. Quando, por exemplo, pensamos atingir a simplicidade absoluta e infinita de Deus, como ao mesmo tempo nos sabemos compostos e finitos, percebemos a falsidade daquela nossa percepção de Deus, pois tudo o que se recebe, recebe-se segundo o modo do receptor, e portanto sabemos que recebemos de um modo finito o que é infinito, ignorando assim sua real infinidade. Contudo, por baixo de sua finita condição, o entendimento percebe o seu ser, e conseqüentemente também a infinidade do ser divino. Por quê? Porque percebendo que é próprio de sua natureza negar o falso e afirmar o verdadeiro, escolherá antes negar aquele seu falso atingir a simplicidade absoluta e infinita de Deus, do que, contra a sua natural inclinação, afirmá-la. Termina o glosador anônimo dizendo que por caminhos semelhantes sabemos existirem na coisa conhecida muito mais e mil vezes mais do que nossa mente possa extrair dela, dado que esta recebe somente as espécies mas não as coisas na sua realidade. ${ }^{23}$

22 S. Agostinho, De Trinitate, XIV, 6,8, citado por E. Forment, Lecciones de Metafisica, Ediciones Rialp, Madrid 1992, p. 165.

23 Eis a glossa completa: "Manifestum est omnibus et experientia quotidiana docet, quod homo per potentias suas cognoscit et investigat veritates entium; et sine ipsis nihil posset. Et quia verum scire quaerimus, quod est, cum causas effectuum attingimus, quae occultae et secretae sunt et 
Com estas palavras, o glosador mostra como a doutrina de Lúlio sobre o conhecimento humano supera uma dificuldade que era bem conhecida por todos na sua época.

\section{O conhecimento do ato de ser dos entes}

Lúlio é conhecido sobretudo por ter desenvolvido um sistema que visa o conhecimento unificado do real. Deu-lhe o nome genérico de Ars e, ao longo de sua vida, elaborou diversas versões do mesmo, sendo a última delas a Ars Generalis Ultima, terminada em 1308.24

A Ars busca concluir proposições verdadeiras; porém, como no realismo luliano a verdade das proposições verdadeiras depende da verdade real da coisa fora da mente, ${ }^{25}$ esta última é a que interessará à Ars.

É sabido que nos entes encontram-se diversas determinações cuja origem deve ser procurada no que denominamos "formas". Todavia, convém muito distinguir adequadamente entre as formas tal como se encontram nos entes concretos corporais e as formas pensadas pelo entendimento humano.

No primeiro caso, a forma faz com que o ente seja tal, em vez de ser tal outro, e, ao mesmo tempo, situa esse ente na ordem real. O fato de um corpo, por exemplo, ser o corpo de um homem, deve-se à participação desse corpo na forma "alma humana". Sob essa perspectiva, as formas são atos. Contudo, deve-se ter em conta que quando a forma completa uma substância - por exemplo, nos entes compostos de matéria e forma - como a substância é sujeito de um atc de ser que por sua vez sustenta 0 ato da forma, sob essa nova perspectiva, isto é, considerando a forma em relação ao ato de ser, a forma deve ser vista como potência. ${ }^{26}$

effectus quandoque manifesti et sensibiles, quandoque et quandoque non. Et tunc scire elevatur magis et oportet artificialiter intellectum ascendere et se suis sororibus adiuvare et sic seipsum cogere et quandoque seipsum transcender et suum naturale intelligere negare et captivare. Et hoc cadit maxime in Deo et in suo opere, ut dum intellectus, qui simplicitatem absolutam et infinitam Dei credit attingere, sciens, quod cum sit finitus et compositus respectu simplicitatis Dei, scit se falsum de Deo attingere, quia de Deo nihil potest recipere nisi secundum suum recipiendi modum. Cognoscit ergo se recipere finite, quod infinitum est, ignorans infinitatem. Tamen infinitatem esse attingit, ita quod infra suam finitatem vel quantitatem attingit esse. Et quia naturaliter habet negare falsum, et inclinationem naturalem habet ad verum affirmandum, potius eligat negare suum falsum attingere, quam affirmare contra suam naturalem inclinationem et perfectionem. Et cognoscit plus esse in re millesies et amplius valde, quam suum attingere possit a rebus haurire, eo quod speciem accipit et non rem. Et similiter cognoscit rationem suam variabilem, rem vero vel obiectum immutabile. Potentias ergo et obiecta earum et actus earum similiter utiliter oportet bene cognoscere, ut hic eas assumimus. "Potentia" enim nomen est aequivocum" Cf. Thomas Le Myésier, Breviculum, Pars Dispositiva, XIX, Corpus Christianorum Continuatio Mediaevalis, vol. LXXVII, Brepols, Tumholt 1990, p. 98.

24 Sobre o sentido da Ars, cf. Esteve Jaulent, Transcendência e imanência na Ars luliana, Consecratio Mundi - Festschrift em homenagem a Urbano Zilles, Edipucrs, Porto Alegre: 1998, p. 370-387.

25 "Sed quia veritas propositionum verarum in intellectu dependet a reali veritate obiecti extra intelectum vel animam" Cf. Thomas Le Myésier, Breviculum, Pars Dispositiva, Praef., Corpus Christianorum Continuatio Mediaevalis, vol. LXXVII, Brepols, Tumholt 1990, p. 56, 1. 267-270.

26 As formas são principios passivos de determinação do ser. Diz-se princípio passivo porque como não há nada acima do Ser, este nunca poderá ser determinado por algo superior a ele - à maneira como, por exemplo, uma forma determina uma matéria ou, em termos mais gerais, como a potência é determinada pelo ato. O Ser é ato, e se tiver de ser determinado por algo, só poderá sê-lo por uma potência, isto é, degradando-se a ser tal. 
Portanto, como é pela forma que o ente se determina a ser tal, para conhecermos um ente será condição necessária conhecermos as suas formas. Mas diz-se que é condição necessária e não suficiente, justamente porque quando pensamos as formas, estas revelam uma perfeição que é a perfeição.própria delas, uma perfeição definida por um gênero e uma espécie; contudo, essa perfeição é distinta da que se obteria ao olhar para a forma do ponto de vista do ato de ser da substância. ${ }^{27}$ Como se viu, nesta segunda perspectiva o ato da forma é sustentado pelo ato de ser da substância.

Voltando ao exemplo anterior, a forma "alma" humana confere ao homem o ser não apenas animal mas também racional; enquanto que a "alma" do animal dá o ser só animal. Portanto, a forma que confere a animalidade ao homem não é a mesma da que confere a animalidade, por exemplo, ao asno; embora nocionalmente só se possua para ambas animalidades um único conceito: a vida sensitiva. Ocorre isto porque ao conhecer unificamos, mas unificamos apenas no conceito ou noção, não na ordem do real..$^{28}$

Vemos, pois, a necessidade de conhecermos as formas desde a perspectiva do ser - para assim obtermos a verdade real da coisa, em termos lulianos - e a insuficiência de nos contentarmos apenas com formas pensadas ou, o que é a mesma coisa, com noções.

Lúlio, na sua Ars, busca a verdade real da coisa e em decorrência disso verá todos os entes sob a perspectiva do seu ato de ser. Como autêntico filósofo, quer conhecer o ente concreto empírico. De modo algum monta um universo de essências. A Ars luliana será um método para se conhecer o universo de verdades reais, desde as mais elevadas até os corpos mais ínfimos. Tendo este objetivo, terá de basear-se nas intentiones primae, ou sinais mentais das realidades exteriores, e acabará sendo tanto uma Lógica como uma Metafísica. Ora, como os atos que sustentam as formas presentes nos entes são inteligiveis - pois são ser, e o ser confere inteligibilidade - poderá haver uma lógica deles. Mas essa lógica não será uma lógica de conceitos, ou de nomes, pois não se pode ter do ato de ser nem um conceito nem um nome, por tratar-se de um ato que comporta movimento e atividade. A Ars luliana será uma lógica das lógicas, uma lógica primeira de atos, um logos, que abrange todo o ser, porque o ser, como o ato, é inteligivel. ${ }^{29}$

27 Cf. Tomás de Aquino, S. Theol., I-II, q. 51, a. 1: "Perfectio autem formae potest dupliciter considerari: uno modo secundum ipsam formam; alio modo secundum quod subiectum participat formam [...] Non autem ista distinctio procedit secundum hoc quod forma habeat esse praeter mateniam aut subiectum, sed qui alia est consideratio eius secundum rationem speciei suae et alia secundum quod participat in subiecto."

28 "En lo compuesto de materia y forma, el género se toma de la materia y la diferencia de la forma, no entendiéndose sin embargo materia como materia primera sino como aquello que por la forma recibe cierto ser imperfecto y material con respecto a su ser específico, como animal es imperfecto y material con respecto a hombre. Sin embargo esas dos maneras de ser no se deben a dos formas diferentes sino a una sola, que da al hombre que sea no sólo animal sino también que sea hombre. Mas el alma de las bestias les da sólo el ser animales, de allí que el animal en tanto género no sea uno en la realidad sino sólo en la noción, porque no por una sola y misma forma son animales el hombre y el asno" Cf. Tomás de Aquino, Las creaturas espinituales, Traducción de Ana Mallea, estudio preliminar y notas de Celina A. Lértora Mendoza, Ediciones del Rey, Buenos Aires 1995, p. 18, n. 24.

29 cf. Esteve Jaulent, opus cit. p. 376-377. 
A Ars luliana é inventiva, isto é, constitui um mecanismo que tem como finalidade a descoberta (invenire). A invenção é a função mais alta da inteligência, superior até a demonstração, que apenas pretende investigar se a noção que se encontrou do real coincide com ele. A Ars luliana exige que a inteligência permaneça sobretudo nessa sua mais alta função, justamente para encontrar o ato de ser dos entes. $\mathrm{O}$ sistema necessariamente terá de ser complexo porque precisará evidenciar as diferenças reais, mas as diferenças da realidade não são diferenças de idéias, noções ou palavras.

Existe uma unificação das idéias, uma unificação das palavras e uma unificação do mundo real, porque tanto uns como outros são diferenciados. Pois bem, é a terceira destas unificações a que Lúlio procura com a sua Ars. E o consegue ao colocar-se na perspectiva do ato de ser. A unificação é necessária porque os atos por si mesmos são internamente diferenciados. Não são iguais 0 ato de ver e 0 ato de pensar. Jesús de Garay alerta para a necessidade de afastarmos uma falsa noção de ato como se tratando de uma energia absolutamente indeterminada, susceptivel de receber formas diversas. Não; os atos possuem as suas formas e são diferenciados. ${ }^{30}$

Não é aqui o lugar para expor o mecanismo da Ars. Foi feito em outros trabalhos. ${ }^{31}$ Basta apontar seu objetivo. A Ars permite analisar os entes a partir de seus princípios constitutivos, captando as diferenças do ser ao nivel do real, aproximando-se assim do ato de ser de cada ente e colocando-se desta maneira num plano totalmente distinto da lógica aristotélica, que se reduz a apreender as diferenças conceituais.

\section{A noção de substância em Lúlio}

Aristóteles afirmava que investigar os princípios e as causas dos entes é investigar a substância. ${ }^{32}$ Dentre as diversas explicações sobre a substância que a filosofia já tinha dado, cabe assinalar duas posições extremas. Por um lado, os platônicos, por adotarem na sua investigação uma perspectiva lógica, afirmavam

30 "El ser es lo innombrable, lo inconceptualizable; pero no porque sea irracional, sino porque el nombre o la idea no son lo único inteligible. La lógica de las palabras o la lógica de ideas no son las únicas lógicas. La lógica de los actos humanos, p. ej., no es la lógica de nombres ni de ideas, pero es lógica. El ser no es actividad informal e indiferenciada. Todo acto posee una forma, en tanto que está internamente diferenciado. El acto de ver no es el acto de pensar, aunque ambos sean acto. Hay que rechazar la visión imaginativa del acto que lo supone como una energia absolutamente indeterminada que puede recibir formas diversas. Los actos, por el contrario, se diferencian. Lo pensado posee una unidad aun cuando las ideas o las proposiciones sean distintas; lo mismo pasa con las palabras: pues bien, también el mundo del acto (esto es, el mundo real) está diferenciado: lo que súcede es que sus diferencias no son como las diferencias entre las ideas o entre las palabras" Cf. Jesús de Garay, Los sentidos de la forma en Aristóteles, Eunsa, Pamplona 1987, p. 150.

31 Entre outros artigos, podem se consultar com proveito Robert Pring-Mill, The lullian 'Art of finding truth": a medieval system of enquiry" Catalan Review, v. 4, 1990, 55-74; Armand Llinarès, "Sens et portée de l'Ars Generalis Ultima de Lulle" in Studia historica et philologica in honorem M. Batllori, Roma, 1984, p. 851-866; e Esteve Jaulent, opus cit. p. 370-387.

32 "De substantia quidem theoria est" Metaf. L. 12, c. 1, 1,17 Cf. Tomás de Aquino, In Metaphysicam Aristotelis Commentaria, Marietti, 1935, p. 681. "A substância é o objeto de nossa pesquisa, pois os princípios e as causas que buscamos são os das substâncias" Cf. Metafísica, L. XII, cap. 1, 1.1012, Editora Globo, Porto Alegre 1969, p. 248. 
que as coisas universais são mais propriamente substâncias que as particulares e por esse motivo situavam as causas das substâncias nos universais e não nos entes singulares ou particulares. No outro extremo, Demócrito e Empédocles tinham dito que tanto as substâncias como os princípios das coisas eram coisas singulares, como o fogo e a terra..$^{33}$

Aristóteles fugirá dos dois extremos e, afirmando que a metafísica deve tratar do ente per se, do ente extra animam, rejeitará fortemente o platonismo, negando a subsistência dos universais. Contudo, o Estagirita admitirá que não apenas os corpos simples são substâncias, mas também os compostos, como os animais e as suas partes. Diz assim em sua metafísica que "chamamos substância os corpos simples, isto é, a terra, o fogo, a água e tudo o mais dessa espécie, bem como, em geral, os corpos e as coisas que deles são compostas, tanto os animais e os seres divinos como as suas partes". ${ }^{34}$ Como já fol indicado mais acima, parece que chega a essa conclusão, porque originariamente estabelece a noção de substância a partir da estrutura predicativa da linguagem. Essas são as suas palavras: "Tudo isso se diz substância porque não é predicado de um sujeito, mas tudo mais é disso predicado." ${ }^{35}$ A primeira preocupação de Aristóteles, portanto, parece que era esclarecer o sentido da predicação.

Muito embora já estivesse na posse das noções de ato e potência, Aristóteles debruçar-se-á sobre a substância principalmente mediante o par matéria-forma, por não terem as noções aristotélicas de ato e potência, como se viu na primeira parte deste trabalho, a plenitude de sentido que só virão a ter mais adiante, quando se identificar ato com ser.

Lúlio todavia, premido por seu forte realismo, buscará construir sua noção de substância a partir de sua concepção tridimensional da estrutura dos entes, principalmente a partir do ato.

Seu primeiro objetivo, como é obvio, será o ente extramental, a substância primeira; não o pensamento. É cìro, todavia, que a substância primeira individual haec - não pode ser definida, por ser já algo fechado em si mesmo. Mas em termos gerais, sim; e Lúlio definirá pois a substância como "o ente que existe por si mesmo" - ens, quod per se existit ${ }^{36}$ - entendendo-se ser ou existir por si mesmo ${ }^{37}$ como ser pelos princípios primitivos da substância que, segundo o maiorquino, são a forma e a matéria. ${ }^{38}$

33 Cf. Tomás de Aquino, In Metaphysicam Aristotelis Commentaria, Marietti, 1935, n. 2423.

34 Cf. Metafisica, L. V, cap. 8, 1. 10-13, Editora Globo, Porto Alegre 1969, p. 121.

35 Cf. Metaf. L.V, Cap. 8, 1. 13-15 in Tomás de Aquino, In Metaphysicam Aristotelis Commentaria, Marietti, 1935, p. 288 "Haec autem omnia dicuntur substantia, quia ṇon de subiecto dicuntur, sed de iis alia" Cf. Metafisica, L. XII, cap 1, 1.10-12, Editora Globo, Porto Alegre 1969, p. 121. Cf. Raimundus Lullus, Die neue logik - Logica Nova, opus cit. p. 84, C.

Lúlic chama de regra $\mathrm{E}$ à pergunta pelo porquê de algo. Esta pergunta pode ter dcis sentidos. No primeiro, ao perguntar - por quê? - perguntamos fundamentalmente pelas causas; no segundo, pelo primeiro sentido do fim. No primeiro sentido, o homem existe porque é composto de alma e corpo; no segundo, dever-se-ia responder que o homem existe para lembrar, entender, amar, honrar e servir a Deus Cf. Raimundus Luluus, Die neue logik - Logica Nova, opus cit. p. 30, E. A forma e a matéria devem ser entendidas sempre analogamente, dependendo da substância individual a que nos estejamos referindo: o fogo tem a sua forma e a sua matéria; o sol, também; e os anjos têm a sua forma e a sua matéria espiritual Cf.id. id., p. 151 C2. 
Contudo, tenha-se em conta que a Ars luliana é um mecanismo de acesso metafísico e lógico ao ente extramental que oferece muitos caminhos. Quando o maiorquino aplica sua Ars na Nova Lógica, estuda os dez predicamentos e formula e responde, a respeito da substância, às dez perguntas ou regras, com as suas subespécies, que resumem todas as dúvidas que podem ocorrer na investigação de qualquer objeto. Lúlio examina a substância a partir de perspectivas diversas, e a define a partir dos principios co-essenciais e naturais, isto é, sem considerar seus acidentes. A examina também estando já em outros, - in alio - isto é, em conjunto com seus acidentes, pois, segundo Lúlio, a substância só subsiste com seus acidentes. Da mesma maneira, ao considerar o dominio que a substância tem sobre outros, afirma que causa os acidentes e seus atos. Lúlio, finalmente, estudará a substância a partir dos princípios primitivos que revelam de que é feito o ente; a partir das causas, etc. Todavia, em todos estes casos, a perspectiva é sempre a do ato de ser, como conectivo de uma potência e um objeto.

Foge ao escopo deste trabalho desenvolver a teoria luliana da substância; basta enfatizar que o maiorquino, ao definir a substância, ${ }^{39}$ situa-se sempre na perspectiva do ato, que é a perspectiva utilizada em sua Ars. Por isso mesmo afirma, em termos muito gerais e utilizando a terminologia que inventou para expressar sua concepção do real, que a substância é feita de um "substantivo", um "substanciável" e o ato de "substanciar" ${ }^{40}$ Em decorrência disso, será próprio da suostância o substanciar, e assim sendo, poder-se-á sempre definir também a substância pelo seu ato próprio. Assim, Lúlio definirá o homem como "animal homificante", isto é, o animal que humaniza tudo quanto se relaciona com ele.

$\mathrm{O}$ ato próprio de cada substância depende de seu ser e de sua essência. Como no homem existem diferentes potências, Lúlio estabelece e fundamenta os atos humanos acima da estrutura correlativa das potências, de tal modo que as partes ativas da imaginação, da sensibilidade, da vegetativa e da elementativa constituem a forma do corpo humano, e as partes passivas das mesmas, a sua matéria. Trata a alma da mesma maneira, de tal modo que as partes ativas do entendimento, da memória e da vontade constituem a forma da alma, e as partes passivas, a matéria. $\mathrm{O}$ ato do homem implica o ato da alma e o ato do corpo, ${ }^{41}$ "pois "home és substància ajustada de ànima racional e de cors elementat, vegetat,

39 Lúlio fornece quatro espécies de definição. Na segunda delas pergunta-se pelas partes coessenciais do sujeito. Como quando perguntamos o que tem de co-essencial e natural a substância do homem, e respondemos "corpo e alma", que são suas partes co-essenciais, substanciais e naturais Cf. Raimundus Lullus, Die neue logik - Logica Nova, opus cit. p. 28, C.2.

40 Cf. "Habet namque substantia inse naturaliter et primarie formam et materiam et coniunctionem, quae sunt de sua essentia. Per formam est substantiva, per materiam est substantiabilis, per coniunctionem habet substantiale substantiare. "Raimundus LulLus, Die neue logik - Logica Nova, opus cit. p. 30, E. Note-se como Lúlio utiliza os termos matéria e forma de maneira análoga, e só nos casos pertinentes utilizará o termo "matéria" no sentido da física aristotélica. Matéria e forma são, em Lúlio, princípios de ser e de compreensão e não entes empiricos. Para a discussão sobre a substituição do hilemorfismo universal pelo acto-potencialismo universal leiam-se as esclarecedoras observações de Celina Lértora Mendoza em Tomás de Aquino, Las creaturas espirituales, opus cit., p. XLIV-XLVII.

41 Cf. Robert D. F. Pring-Mill, El microcosmos llul.lià, in Estudis sobre Ramon Llull, Curial, Publicacions de la Abadia de Montserrat, Barcelona 1991, p. 102-110. 
sensat e yimaginat", ${ }^{42}$ o homem é uma substância ajustada de alma racional e de corpo elementado, vegetado, sensitivado e imaginado. Por este procedimento, o ato de ver, ou o de sentir, por exemplo, nunca poderão identificar-se nem assemelhar-se aos atos de ver ou de sentir animais, pois no homem se encontra a potência racional que não existe nos animais, e portanto, cada ato de visão ou cada sentimento humano, de alguma maneira, terão relação com a racionalidade.

A título de exemplificação, e finalizando esta parte, leiam-se as palavras do maiorquino no seu Livro do Ascenso e Descenso do Entendimento: "Os atos do homem são semear, costurar, vestir, montar a cavalo, pintar, atirar flechas, comprar, vender, escrever, ler, ensinar, fazer oração, julgar, etc. E porque estes atos apenas competem ao homem e não a outro animal, convém que o entendimento investigue o porquê, e para tanto que considere que no homem há mais ser e essência que no leão, porque o ser do homem é racional e a sua essência a racionalidade, na qual se encontra o entender, o amar e o lembrar, que são próprios da essência racional, com os quais tem atos mais elevados e nobres que o ente irracional." 43

\section{A incorporação da verdade conhecida}

Lúlio distingue entre as diferentes potências do homem e entre cada uma delas e o próprio homem; contudo esclarece que as potências atuam na medida em que atua o homem, pois este último move cada uma delas como o todo move as suas partes. ${ }^{44}$ Além disso, pela sua concepção correlativa do ato, o intelecto humano é associado à bondade, à grandeza, à duração, ao poder, à vontade, à virtude, à verdade, ao deleite, etc., pois é criado pelo intelecto divino e portanto pela sua bondade, grandeza, etc. Devido a essa associação, o intelecto precisa da ajuda da memória e da vontade para entender e quanto maior for a ajuda dessas potências irmãs, melhor o desempenho do entendimento, ${ }^{45}$ até tal ponto que, quando há no homem um desejo muito forte de algum erro, o intelecto pode enganar-se nos seus julgamentos. "Ele [o homem], diz o Intelecto, move-me, assim, como o todo move as suas partes. E, por isso, devido a ele, se enganado, falho contra minha natureza, não por mim, mas porque às vezes o homem tem uma tão grande vontade para o desejado, que eu não tenho liberdade de anteceder nem de inquirir a verdade." $" 46$

42

43

44

45

46

Cf. ORL XXI:26) citado por Robert D. F. Pring-Mill, opus cit., p. 102-110.

Cf. Ramon Llull, Libro del Ascenso y Descenso del Entendimiento, Ediciones Orbis S/A, Barcelona 1985, p. 77.

"De novo disse o Intelecto: Entre mim e o homem, no qual estou, há diferença, visto que sou uma parte dele. [...] O homem, no entanto, é composto de várias potências. Ele move-me, assim como o todo move as suas partes Cf. Ramon Lluil, O Livro da Lamentação da Filosofia, Tese e tradução do Liber Lamentationis Philosophiae para a obtenção do grau de Mestre em Filosofia pcr Brasilia Bernadete Rosson, sob a orientação de Luis Alberto de Boni, Porto Alegre 1997, inédita, p. 168.

Intellectus, cum intelligit unam similitudinem, cum concordat et unam speciem cum alia, et cum ignorat, non potest habere illam concordantiam. Et si memoria et voluntas magnum iuvamen faciunt potentiae ad concordandum unam similitudinem et speciom cum alia, intellectus talem habet operationem cum iuvamine, quam habere non potest per se sine iuvamine" Cf. Thomas Le Myésier, Breviculum, Pars Dispositiva, XIX., Corpus Christianorum Continuatio Mediaevalis, vol. LXXVI, Brepols, Turnholt 1990, p. 170, 1. 76-81.

Cf. Ramon Llull, O Livro da Lamentaçāo da Filosofia, opus cit. p. 168. 
O maiorquino lembrará sua doutrina dos atos próprios, ou substanciais, e dos atos apropriados, ou acidentais, para explicar a conservação dos conhecimentos adquiridos. Esclarece em primeiro lugar que a ação própria do intelecto não é predicamental, mas substancial ou primitiva, "porque se converte com a própria forma"; 47 por ela entendemos nosso próprio entender. ${ }^{48}$ Todavia, essa ação não predicamental originará também os atos acidentais predicamentais mediante os quais conhecemos os outros entes reais. Como, por outro lado, os atos acidentais possibilitam e aperfeiçoam os substanciais, por habituarem a substância a modos de ser mais perfeitos, resta concluir que entendermos com ajuda da memória e da vontade os entes reais extramentais significa incorporar suas verdades em nosso ser.

Não cabe, pois, no lulismo, um conhecimento frio, puramente cerebral, limitado ao intelecto. Se realmente conhecemos, incorporamos o conhecido à nossa vida, e isto porque o intelecto é vida e dá a vida ao corpo. "Sou vida, diz o Intelecto; e enquanto sou vida, sou vida e forma do corpo com o qual estou conjunto [...] O próprio homem é perfeito através de mim e me move a entender, visto que minha natureza é entender, e isso naturalmente."49

Gostaria de terminar este trabalho dizendo, com terminologia mais atual, que se no aristotelismo o lugar das idéias é o entendimento, no lulismo o lugar das verdades é a pessoa.

Cf. Ramon Llull, O Livro da Lamentaçăo da Filosofia, opus cit. p. 167.

4 Novamente aparece a doutrina primigênia da potência-ato-objeto como fundamento de uma explicação. 